\title{
Automated analysis of morphological change in the duodenal mucosa of children with coeliac disease
}

\author{
E A M TULLOH, J M BAYLIS, AND D N CHALLACOMBE \\ Somerset Children's Research Unit, Taunton and Somerset Hospital
}

SUMMARY A modular image analysing system was used to study the morphology of the duodenal mucosa in children with coeliac disease and to compare it with normal duodenal biopsies. The results suggest that this automated method of tissue analysis is useful for the routine analysis of small intestinal biopsies.

Peroral small intestinal biopsy has become an important investigation in patients with suspected malabsorption. Severe or specific histological abnormalities can generally be identified easily by light microscopical examination but minor abnormalities are more difficult to assess; therefore a technique that can quantify accurately and rapidly any structural change in the small intestinal mucosa is needed. Methods using measurements of villous height and mucosal thickness have been described using a projected image of a mucosal section, ${ }^{12}$ or an eyepiece micrometer. ${ }^{3}$ Point-counting techniques and intercept measurements have been reported too using an eyepiece grid in a light microscope. ${ }^{45}$ However such methods are time-consuming and inter-observer differences limit their routine use. Morphological changes in the small intestine have been assessed by computer also ${ }^{6-8}$ and the development of automated morphometric methods may prove to be of value in the routine analysis of small intestinal biopsies.

We report the use of a modular image analysing system (Kontron MOP/AMO2) for studying the morphology of the duodenal mucosa in children with coeliac disease. The results were compared with results from children with normal duodenal biopsies.

\section{Patients}

Three groups of children were studied. The first group comprised 7 boys and 2 girls, aged between 3 months and 5 years (mean 21 months), who were being investigated in hospital for failure to thrive. The appearances of their duodenal biopsies on light microscopical examination were considered to be normal. The second group comprised 5 boys and 4 girls, aged between 5 and 26 (mean 10) months, with coeliac disease. Duodenal biopsies in these patients had shown a flattened mucosa and in each a glutenfree diet had led to clinical recovery. The third group comprised 4 girls, aged between 5 years 10 months and 7 years 4 months, on whom a diagnosis of coeliac disease had been made in infancy. These patients had been on a gluten-free diet for several years and had then been challenged with gluten powder (Energen) for 3 months to find out if they still needed a gluten-free diet. Gluten powder was added to their gluten-free food in a dose of $2 \mathrm{~g}$ a day for 1 week, $5 \mathrm{~g}$ a day for 3 weeks, and $10 \mathrm{~g}$ a day for the rest of the 3 months. All these patients had developed gastrointestinal symptoms on the gluten challenge and biopsies after the challenge had shown villous flattening. They were therefore advised to stay on a gluten-free diet for life.

\section{Duodenal biopsy}

Peroral small intestinal biopsies were obtained from the distal duodenum under fluoroscopic control in all patients, using a Watson paediatric biopsy capsule. Tissue was removed from the capsule, viewed under a Wild M 7 dissecting stereomicroscope and orientated with the mucosal surface uppermost on to a small square of black card. The tissue was then fixed in $10 \%$ formol saline for 2 hours, processed conventionally, and embedded in paraffin wax, using a magnifying lens to ensure that sections were cut perpendicularly with the villous surface. Sections of the duodenal mucosa were then cut at a thickness of $5 \mu \mathrm{m}$ and stained with haematoxylin and eosin.

\section{Image analysis}

The modular image analysing system (Kontron MOP/AMO2), consists of a glass evaluating tablet $(280 \times 280 \mathrm{~mm})$ and a stylus connected to a minicomputer. The active measuring area on the glass 
tablet overlies magnetised steel wires spaced at regular intervals in $\mathrm{X}$ and $\mathrm{Y}$ directions to form a magnetic field. Current impulses emitted from the sides of the evaluating tablet induce magnetostrictive pulses in the steel wires, which are intercepted when contact is made between the stylus and the surface of the tablet. A coil within the stylus registers the pulses, determines the co-ordinates of the stylus tip on the evaluating tablet, and these co-ordinates are transformed simultaneously into geometric parameters such as length and area by the minicomputer, according to a preselected programme.

Stained sections of the duodenal mucosa are viewed under a Leitz Dialux 20 EB light microscope with a drawing tube attachment, using a $\times 10$ eyepiece and $a \times 6.3$ objective, which give a final viewing magnification of $78 \cdot 75$. Measurements are only made on duodenal tissue lying within the perimeter of a $1 \mathrm{~cm}$ square grid (Graticules Ltd), inserted into one eyepiece of the binocular microscope. The drawing tube attachment enables the image of a light-emitting diode at the end of the stylus to be superimposed on the duodenal section. Morphometric analysis of each section is performed by tracing the image of the light-emitting diode around the perimeter of the duodenal section. As the stylus incorporates a ballpen, with appropriate pressure the perimeter can simultaneously be drawn on a thin sheet of paper placed on the evaluating tablet while activating the selected measurement function (Figure ). Complete analysis of 3 alternate
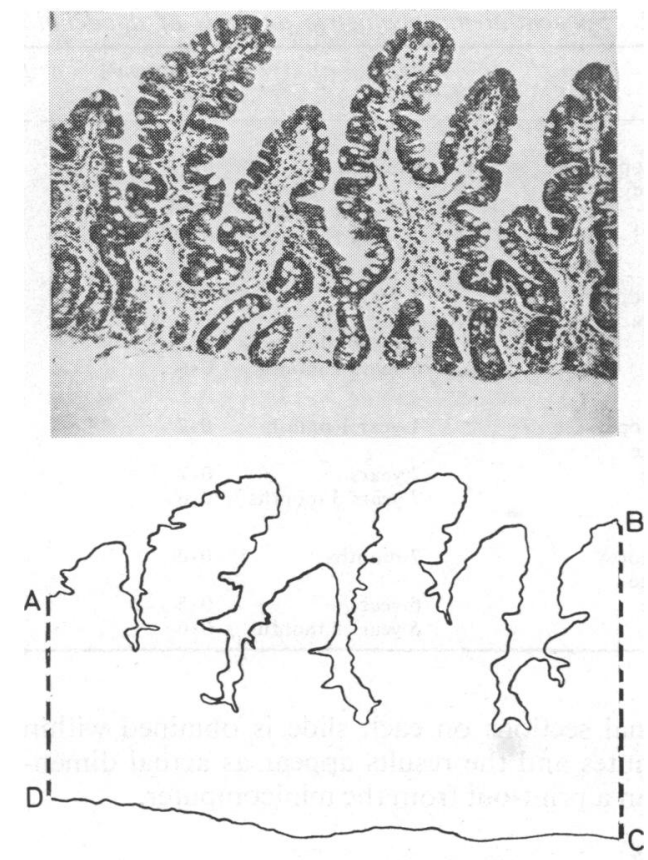

$A-B=$ length of surface epithelium $D-C=$ length of muscularis mucosa MUCOSAL INDEX $=\frac{A B}{D C}$

Figure Tracing obtained of the duodenal mucosa with definition of measurements used in the text.

Table 1 Morphometric analysis of duodenal mucosa from patients with coeliac disease and controls

\begin{tabular}{|c|c|c|c|c|c|c|c|}
\hline Controls & Age (months) & Sex & Area $\left(\mathrm{mm}^{2}\right)$ & Perimeter $(\mathrm{mm})$ & $\begin{array}{l}\text { Muscularis } \\
\text { mucosae }(\mathrm{mm})\end{array}$ & $\begin{array}{l}\text { Surface } \\
\text { mucosa }(\mathrm{mm})\end{array}$ & $\begin{array}{l}\text { Mucosal } \\
\text { index }\end{array}$ \\
\hline $\begin{array}{l}1 \\
2 \\
3 \\
4 \\
5 \\
6 \\
7 \\
8 \\
9\end{array}$ & $\begin{array}{r}3 \\
4 \\
6 \\
7 \\
9 \\
18 \\
33 \\
48 \\
60\end{array}$ & $\begin{array}{l}\mathbf{M} \\
\mathbf{F} \\
\mathbf{M} \\
\mathbf{M} \\
\mathbf{M} \\
\mathbf{M} \\
\mathbf{M} \\
\mathbf{M} \\
\mathbf{F}\end{array}$ & $\begin{array}{l}0.5 \\
0.6 \\
0.9 \\
0.6 \\
0.5 \\
0.7 \\
0.5 \\
0.8 \\
0.5\end{array}$ & $\begin{array}{r}8 \cdot 7 \\
10 \cdot 3 \\
10 \cdot 4 \\
8 \cdot 8 \\
10 \cdot 1 \\
11 \cdot 5 \\
8 \cdot 7 \\
11 \cdot 5 \\
8 \cdot 9\end{array}$ & $\begin{array}{l}1.6 \\
1.6 \\
1.7 \\
1.6 \\
1.6 \\
1.6 \\
1.7 \\
1.6 \\
1.6\end{array}$ & $\begin{array}{l}6 \cdot 5 \\
7 \cdot 7 \\
7 \cdot 5 \\
6 \cdot 9 \\
7 \cdot 7 \\
9 \cdot 5 \\
6 \cdot 3 \\
8 \cdot 9 \\
6 \cdot 6\end{array}$ & $\begin{array}{l}4 \cdot 1 \\
4 \cdot 8 \\
4 \cdot 4 \\
4 \cdot 3 \\
4 \cdot 8 \\
5 \cdot 9 \\
3 \cdot 7 \\
5 \cdot 6 \\
4 \cdot 1\end{array}$ \\
\hline $\begin{array}{l}\text { Mean } \\
\text { SD }\end{array}$ & $20 \cdot 9$ & & $\begin{array}{l}0.62 \\
0 \cdot 15\end{array}$ & $\begin{array}{l}9 \cdot 87 \\
1 \cdot 15\end{array}$ & $\begin{array}{l}1 \cdot 62 \\
0 \cdot 04\end{array}$ & $\begin{array}{l}7 \cdot 51 \\
1 \cdot 09\end{array}$ & $\begin{array}{l}4 \cdot 6 \\
0 \cdot 72\end{array}$ \\
\hline $\begin{array}{l}\text { Coeliacs } \\
1 \\
2 \\
3 \\
4 \\
5 \\
6 \\
7 \\
8 \\
9\end{array}$ & $\begin{array}{r}5 \\
6 \\
6 \\
8 \\
8 \\
9 \\
12 \\
14 \\
26\end{array}$ & $\begin{array}{l}\mathbf{M} \\
\mathbf{M} \\
\mathbf{F} \\
\mathbf{M} \\
\mathbf{M} \\
\mathbf{M} \\
\mathbf{F} \\
\mathbf{F} \\
\mathbf{F}\end{array}$ & $\begin{array}{l}0.4 \\
0.5 \\
0.7 \\
0.6 \\
0.5 \\
0.7 \\
0.6 \\
0.7 \\
0.5\end{array}$ & $\begin{array}{l}4 \cdot 7 \\
4 \cdot 1 \\
5 \cdot 2 \\
4 \cdot 7 \\
4 \cdot 2 \\
4 \cdot 7 \\
4 \cdot 7 \\
4 \cdot 8 \\
4 \cdot 2\end{array}$ & $\begin{array}{l}1 \cdot 6 \\
1.6 \\
1 \cdot 7 \\
1.7 \\
1 \cdot 6 \\
1.6 \\
1.6 \\
1 \cdot 7 \\
1 \cdot 6\end{array}$ & $\begin{array}{l}2 \cdot 6 \\
2 \cdot 1 \\
2 \cdot 6 \\
2 \cdot 3 \\
1 \cdot 8 \\
2 \cdot 4 \\
2 \cdot 3 \\
1 \cdot 8 \\
1 \cdot 9\end{array}$ & $\begin{array}{l}1 \cdot 6 \\
1 \cdot 3 \\
1 \cdot 5 \\
1 \cdot 3 \\
1 \cdot 1 \\
1 \cdot 5 \\
1 \cdot 4 \\
1 \cdot 0 \\
1 \cdot 2\end{array}$ \\
\hline $\begin{array}{l}\text { Mean } \\
\text { SD }\end{array}$ & $10 \cdot 4$ & & $\begin{array}{l}0 \cdot 58 \\
0 \cdot 11\end{array}$ & $\begin{array}{l}4 \cdot 58 \\
0 \cdot 35\end{array}$ & $\begin{array}{l}1 \cdot 63 \\
0 \cdot 05\end{array}$ & $\begin{array}{l}2 \cdot 2 \\
0 \cdot 32\end{array}$ & $\begin{array}{l}1 \cdot 32 \\
0 \cdot 19\end{array}$ \\
\hline $\mathbf{P}$ & NS & & NS & $<0.001$ & NS & $<0.001$ & $<0.001$ \\
\hline
\end{tabular}

NS $=$ not significant. 
Table 2 Sequential morphometric analysis of duodenal mucosa from 4 girls with coeliac disease

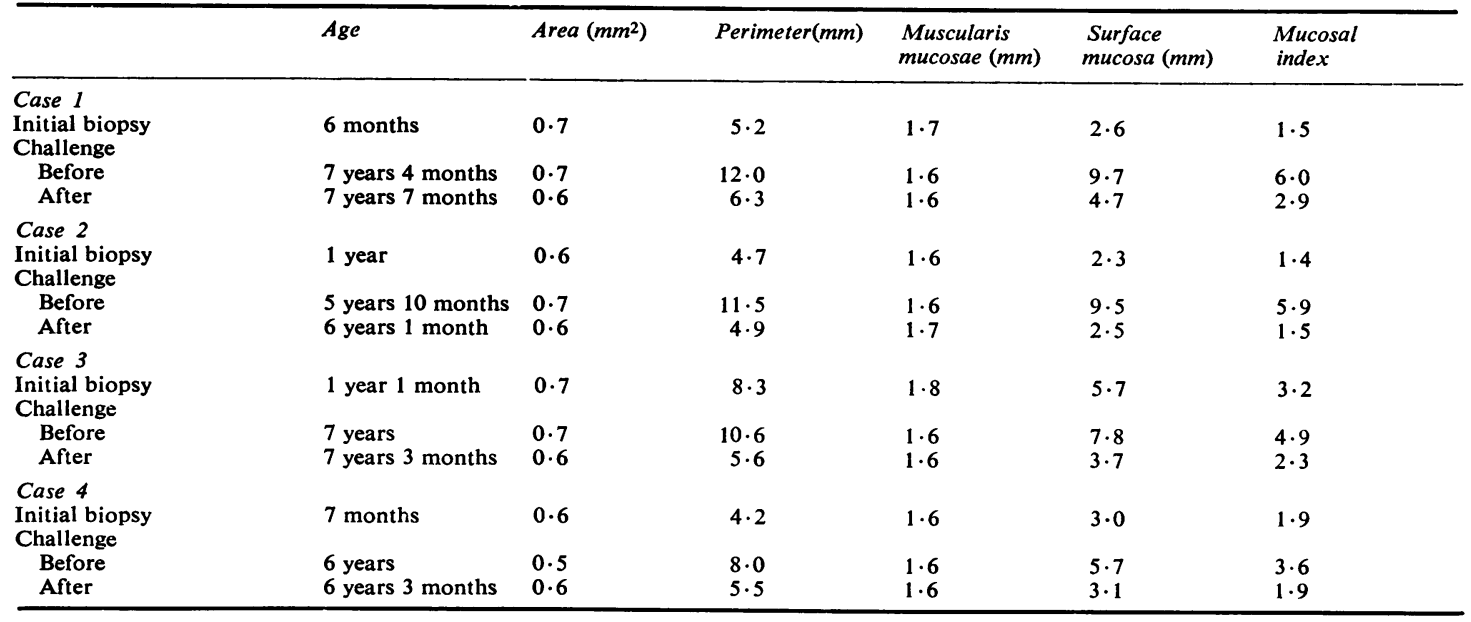

duodenal sections on each slide is obtained within 10 minutes and the results appear as actual dimensions on a print-out from the minicomputer.

\section{Results}

The following measurements were taken on each duodenal section: (1) area of the section $\left(\mathrm{mm}^{2}\right)$; (2) perimeter of the section $(\mathrm{mm})$; (3) length of the muscularis mucosae $(\mathrm{mm})$; (4) length of the surface mucosa $(\mathrm{mm})$. The mucosal index was derived by dividing the surface mucosal length by the muscularis mucosal length. The results (Tables 1 and 2) represent the mean of single measurements made on 3 alternate duodenal sections on each microscope slide. The area of duodenal tissue and the length of the muscularis mucosae in the coeliac patients were compared with those of the controls using Student's $t$ test. Neither the area of duodenal tissue $(P>0.7)$ nor the length of the muscularis mucosae $(\mathrm{P}>0 \cdot 3)$ in each group of patients was significantly different. The length of the perimeter of the tissue $(P<0.001)$, the length of the surface mucosa $(P<0 \cdot 001)$, and the mucosal index $(P<0.001)$ were all significantly smaller in the patients with coeliac disease.

Measurements were also made on duodenal biopsies from 4 children with coeliac disease, firstly in infancy, then after several years on a gluten-free diet, and finally, after gluten challenge for 3 months. The results (Table 2) show the recovery of the flattened duodenal mucosa on a gluten-free diet, with mucosal damage recurring after a gluten challenge.

\section{Discussion}

A semiautomatic method was used to compare the duodenal mucosa from children with untreated coeliac disease with that from normal children. Morphometric studies were performed too on serial duodenal biopsies from 4 children with coeliac disease before and after being placed on a gluten-free diet, and then after a gluten challenge. The mean lengths of the surface mucosa were shorter and the perimeter of each section was smaller in patients with coeliac disease compared with normal biopsies Values for the mucosal index were also significant smaller in patients with coeliac disease. The mean length of the muscularis mucosae and the mean area of the duodenal sections however were not appreciably different between the coeliac patients and the controls. These results confirm previous findings that the mucosal lesion in coeliac disease is not true atrophy. ${ }^{7}$ The flat mucosa is a result of a change in the spatial distribution of tissue, with a fall in the epithelial cell volume being accompanied by a rise in crypt volume. Previous computer-based morphometric studies have used a tracing of a projected image of the small intestinal mucosa, ${ }^{6}$ or a camera lucida image of the mucosa drawn on to computer cards from which an optical mark reader fed structural data into a computer. Recently computer-aided microscopical examination was used to study the jejunal mucosa from adults with coeliac disease.$^{8} \mathrm{~A}$ television camera transmitted a light microscopical image of the mucosa on to a television monitor o screeen and tissue components were defined by a $N$ light-pen, and structural features were analysed by స్ల computer. Our method was quicker than computer- 0 card morphometry and was cheaper than computeraided microscopical examination. The technique was simple to do and the method was sensitive to serial mucosal changes occurring in patients undergoing 
gluten challenge. The findings suggest that this automated method of tissue analysis is of value in the routine examination of small intestinal biopsies.

We thank Mr E E Wheeler for assistance.

The T M Gregory Memorial Fund and the Hong Kong (Trustees) Limited, Hong Kong and Shanghai Bank, provided generous financial support.

\section{References}

1 Doniach I, Shiner M. Duodenal and jejunal biopsies. II. Histology. Gastroenterology $1957 ; 33$ : 71-86.

2 Shiner M, Doniach I. Histopathologic studies in steatorrhea. Gastroenterology 1960; 38: 419-40.

3 Roy-Choudhury D, Cooke W T, Tan D T, Banwell J G, Smits B J. Jejunal biopsy: criteria and significance. Scand J Gastroenterol 1966; 1 : 57-74.

4 Dunnill M S, Whitehead R. A method for the quantitation of small intestinal biopsy specimens. J Clin Pathol 1972; 25: 243-6.

5 Wright S G, Tomkins A M. Quantitative histology in giardiasis. J Clin Pathol 1978; 31 : 712-6.

- Chapman B L, Henry K, Paice F, Stewart J S, Coghill N F. A new technique for examining intestinal biopsies. Gut 1973; 14: 905-9.

7 Meinhard E A, Wadbrook D G, Risdon R A. Computer card morphometry of jejunal biopsies in childhood coeliac disease. J Clin Pathol 1975; 28 : 85-93.

8 Slavin G, Sowter C, Robertson K, McDermott S, Paton K. Measurement in jejunal biopsies by computer-aided microscopy. J Clin Pathol 1980; 33: 254-61.

Correspondence to Dr D N Challacombe, Somerset Children's Research Unit, Taunton and Somerset Hospital, Musgrove Park, Taunton, Somerset TA1 6DA.

Received 6 November 1980

\section{Erratum}

\section{Chemotherapy of advanced neuro- blastoma: does adriamycin contribute?}

Jacques Ninane, Jon Pritchard, and James S Malpas. We apologise for the fact that Fig. 1 (Arch Dis Child $1981 ; 56: 544-8$ ) was incorrect. The correct version is shown below.

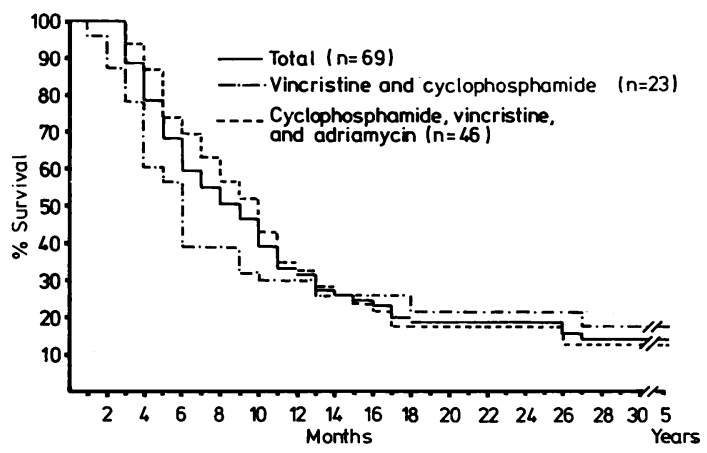

Fig. 1 Survival rate and the effect of adriamycin. 